\title{
What Prompt You to Submit Your Resume? An Empirical Study
}

\author{
Liang Yang ${ }^{1}$, Liangqiang $\mathrm{Li}^{1,}{ }^{*}$, Lu Liu ${ }^{1}$, Miyan Liao", Yunzhong Cao ${ }^{2}$, Xiaolin $\mathrm{Li}^{1}$ \\ ${ }^{1}$ Business School, Sichuan Agricultural University, Dujiangyan, China \\ ${ }^{2}$ College of Architecture and Urban-Rural Planning, Sichuan Agricultural University, Dujiangyan, China
}

Keywords: Online recruitment; Information quality; Recruitment website; Resume delivery

\begin{abstract}
The rapid development of the internet has greatly enriched the methods of company recruitment and improved the efficiency of company recruitment. From the perspective of the third-party online recruitment website, we apply conceptual framework of information quality to explore the factors that influence job-seekers' resume delivery from two aspects: company information and job information. The data for research is obtained through58.com. The results of the study indicate that job-seekers' intentional behavior will be influenced by company (e.g., scale, feedback, day, etc.) and job (e.g. number of recruitments, experience requirements) information in the process of online recruitment. The research results of this paper can not only enrich the application of concept of information quality in online recruitment, but also help improve third-party recruitment websites and optimize the recruitment strategies of a company.
\end{abstract}

\section{Introduction}

Development in information and communications technology has changed traditional human resource functions, and one of the most affected areas is staff recruitment[1]. Monster.com and CareerMosaic.com, the two largest online recruitment websites in the world, both started in 1994 [2]. After decades of development, online recruitment has been widely welcomed by companies and job seekers, with the number of recruitment websites, employers and applicants has grown rapidly. In 2018, the number of online employers in China reached 5.267 million, an increase of 3.5\% compared to the previous year. Many companies purposely choose online recruitment in their growth, because they can communicate with job-seekers in real time through online recruitment, and online recruitment can recruit suitable candidates with higher efficiency and lower costs[3].At present, there are two main types of online recruitment methods for companies, one is the company recruitment website, and the other is the third-party comprehensive recruitment website[4]. Generally speaking, compared with company recruitment websites, it is cheaper to publish recruitment information through third-party recruitment websites and there are more potential job-seekers.

However, most of the existing researchers have studied online recruitment from the perspective of job-seekers, and have focused on the influencing factors and psychological perceptions of job-seekers' participation in online recruitment. Few studies have been conducted from the perspective of third-party recruitment websites to study online recruitment. Based on the above analysis, we obtain real data from 58.com, a third-party recruitment comprehensive website, and analyze the two dimensions(company and job information) from the perspective of a recruitment website to study the impact of recruitment information posted on third-party comprehensive recruitment websites on resume delivery. Through this work, we can provide valuable information to third-party online recruitment websites to improve services, at the same time, to help those companies that need talents to enhance their competitiveness in talent competition.

\section{Literature Reviews}

\subsection{Online recruitment}

Online recruitment is an Internet-based recruitment strategy, including the use of Internet 
advertising, email invitations, online message boards, and social media to find specific groups [5].In academia, many researchers have focused on the effectiveness of online recruitment. Nasreem et al. studied the factors influencing the effectiveness of online recruitment measured through the attributes of advantages and disadvantages[6]. Sultana thought that there are three dimensions of the effectiveness of online recruitment, including online recruitment media preferences, perceived advantages, improvement in recruitment stages, and each of which consists of four to five factors[7].However, most of the researches are conducted from applicants' perspective or recruiters. There is a lack of insight about the effectiveness of recruitment from the recruitment websites.

\subsection{Information quality}

In information systems, information quality(IQ) is applied in various fields and researches. Information quality is defined as the quality of outputs the information system produces, which can be in the form of reports or online screens[8].In our study, we adopt a comprehensive conceptual framework of information quality proposed by Wang and Strong[9], which has been applied to many researches. This conceptual framework consists of four dimensions: Intrinsic Quality, Contextual Quality, Representational Quality, and Accessibility Quality. Meanwhile, each of them consists of several specific indices. As for our research, to verify the factors influencing the behavior of resume delivery on recruitment websites, we chose the two dimensions of contextual quality and representational quality. The reason why we didn't consider accessibility quality is that the rapid development of Internet technology makes it possible for people to access the network anytime and anywhere, especially the popularity of mobile Internet. Thus, accessibility quality not in our consideration.

\subsection{Perception of job-seekers}

What do potential applicants think of the job on the recruitment website? This is what many researchers are focusing on. Mastering the perception of job-seekers in the process of applying for a job can significantly improve the effectiveness of online recruitment. Banerjee et al. analyzed the perceived quality and perceived credibility of applicants for online recruitment websites and the impact on their subsequent willingness to apply, which found that videos and evaluations of real employees provided by third-party recruitment websites has a positive effect on the perceived quality and credibility[1].

In the context of the increasing popularity of online recruitment, there is lack of empirical evidence about the effect of information quality on the intention of job-seekers. Therefore, we intend to investigate which information posted on online recruitment can influence job-seekers' intention to submit resumes by analyzing 58.com, a third-party recruitment comprehensive website in china.

\subsection{Factors influencing intentional behavior}

For the factors that affect the online recruitment resume delivery, some studies divided them into internal and external factors based on importance, while other studies divided them into different stages according to the recruitment process. Alsultanny et al. conducted a questionnaire survey of 356 actual online recruiting users and found that the usefulness, happiness, and ease of use in the online recruitment process have a positive impact on job-seekers' attitudes towards positions, and job search attitudes are significantly related to the final delivery behavior [10]. Parry et al. mentioned the theory of planned behavior, thinking that the intention to perform a specific behavior is based on attitudes and beliefs about the behavior, and job applicants' selection of recruitment websites and jobs is largely based on subjective principles, not the most efficient choice [11]. In the process of online recruitment, we must not only focus on attracting potential job-seekers, but also pay attention to protecting the privacy and safety of job-seekers[12]. Accurately mastering the factors that affect the effectiveness of online recruitment can help both companies and third-party recruitment websites to make corresponding improvements, thereby obtaining more applicant resumes. 


\section{Research hypotheses and model}

\subsection{Company information}

\subsubsection{Reputation}

Reputation refers to a stakeholder group's perceptions of an entity's social standing or overall relative appeal[13]. Generally speaking, the number of companies in the third-party recruitment website is too large to allow a careful review of each company. Meanwhile, the low barriers of entry in the third-party recruitment website result in differences in company quality. Large companies with a high reputation can often reduce job applicants' uncertainty, and they generally accept broad public acceptance. In summary, a company's reputation has a strong influence on prospective applicants' initial attitudes toward it[14],and further influences the behavior of job-seekers. Expectation theory holds that individuals are more likely to be attracted to higher expectations and higher-value jobs, and by transmitting positive company reputation signals, they can positively affect applicants' resume delivery[15]. A high-level company corresponds to a higher reputation. Based on the above analysis, the basic hypothesis of this article is proposed:

H1: Companyreputation has a positive impact on job applicants' resume delivery behavior.

\subsubsection{Believability}

Believability refers to the property of being worthy of being believed by rational and informed users[13]. In the context of online recruitment, job-seekers will try to evaluate the believability of information. Believability comes from attributes involved in available information, such as the number of days to join the recruitment website, whether there is real-name certification authentication issued by the website or not, and so on. In general, the longer a company has joined the recruitment website, the higher reliability it has, which verifies that it has got a good trust by many job-seekers and online recruitment websites. What's more, real-name authentication is a threshold set by recruitment websites to verify the validity of information provided by companies, through which they can filter those unqualified companies and further establish a reliable online recruitment system. Online recruitment information conveys opinions on different behaviors[16], and believability coming from information can mitigate the perception of risk. Based on the above analysis, the following hypothesis is proposed:

H2: Information believability has a positive impact on job applicants' resume delivery behavior.

\subsubsection{Timeliness}

Timeliness is a dynamic process where new information arises to replace the old. Prior empirical evidence shows that applicants interpret time delays as indicative of job and organizational characteristics in the process of recruitment[17].In the context of online recruitment, both the timeliness of communication and the rate of resume feedback will influence job-seekers' intention to deliver resumes. With the above analysis, we hypothesize that:

H3: Timeliness has a positive impact on job applicants' resume delivery behavior.

\subsubsection{Representational quality}

The content of representational quality is that the system should present information in a way that it is easy to understand, visual and easy to use[18].Moreover, Wang and Strong proposed that representational quality includes aspects related to the form of presentation of information and its meaning[9].On third-party recruitment websites, representational quality can be displayed in a variety of forms, such as background, color, text, font, video, audio, image. Sometimes, it will be shown in a form of combination of those factors. We believe that high quality representation can decrease the confusion and difficulty in understanding of information. Meanwhile, multiple forms of information presentation can enhance the vividness of information. The attractiveness to job-seekers is affected by the vividness of the recruitment website and the attributes of the position[19].In the case of online recruitment, we argue that job-seekers prefer those positions with pictures that embodies the culture of the company or working environment. Based on the above 
analysis, the following hypothesis is proposed:

H4: Representational quality has a positive impact on job applicants' resume delivery behavior.

\subsection{Job information}

\subsubsection{Value-added}

Value-added refers to the extent to which data is useful and provides advantages for their use[9].It can be expected that if information posted on websites is valuable for job-seekers, there are more incentives to send their CV. Randolph and Johnson believe that the factors that improve employee satisfaction include internal and external aspects. Among them, internal factors refer to some factors related to the work content, and external factors refer to relevant factors such as the work environment [20]. Specific factors such as salary, benefits, and promotion mechanisms have an important impact on the value perception of job-seekers. Firfiray and Mayo found that the work and life benefits provided by the organization in the recruitment process can match the value perception among some job applicants, thereby increasing the attractiveness of the company to the job applicants [21]. In general, the main purpose of job-seekers' participation in work is to obtain remuneration. Remuneration has an important role in the human resource management of a company. Welfare as a supplement to remuneration can also enhance the job-seeker's perceived value of jobs, thereby prompting candidates to deliver resumes. Based on the above analysis, the following hypothesis is proposed:

H5: Value-added has a positive impact on job applicants' resume delivery behavior.

\subsubsection{Relevance}

Relevance refers to the extent which information is associated with a task[9].The information of recruitment is relevant if it illustrates requirements regarding the number of recruitment or experience. In order to find the right employees, companies must establish certain recruitment criteria. Different jobs require different levels and types of skills, and an efficient production requires formal education and work experience[22]. Generally speaking, with the increase of academic requirements, the number of qualified candidates will decrease accordingly. Similarly, the increase of experience requirements will reduce the number of qualified candidates. In the process of applying for a job, job-seekers especially focus on those jobs which correspond to their competence. Based on community theory, candidates are under pressure from competition and recruitment density [23]. The establishment of company recruitment standards is actually a series of selection and discrimination acts to screen out the most suitable employees for the company. In our research, we did not consider the requirements of educational background in that sales jobs require rich practical skills rather than theoretical knowledge. Based on the above analysis, the following hypothesis is proposed:

H6: Relevance has a positive impact on job applicants' resume delivery behavior.

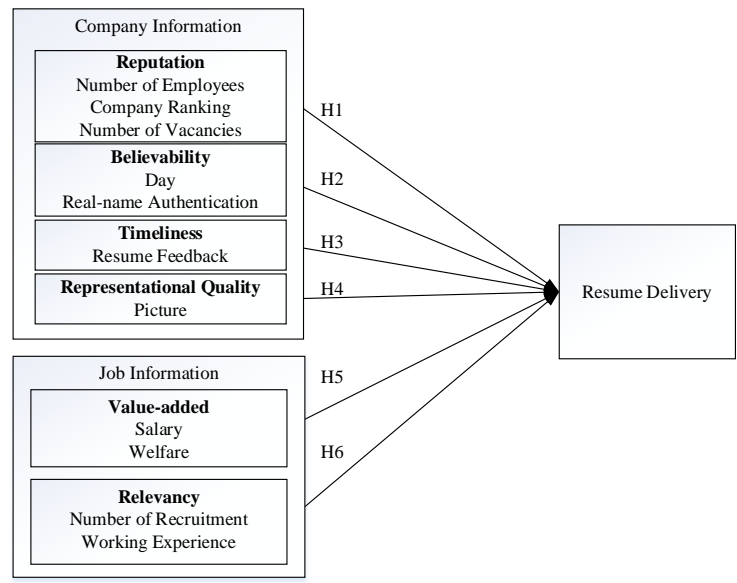

Figure 1 Research model. 


\subsection{Research model}

Based on the above assumptions, this paper proposes the following research model (Figure 1). The model indicates that company characteristics, job characteristics, and perceived usefulness have a direct impact on intentional resume delivery behavior.

\subsection{Variable measurement}

The purpose of this article is to explore the factors that affect resume delivery behavior, so we select resume delivery behavior as the dependent variable. We believe that the intention of job-seekers will be influenced by information from companies and positions. The detailed description of the variables is shown in Table 1.

Table 1 Variable description.

\begin{tabular}{|c|c|c|c|}
\hline Type & Category & Name & Measurement \\
\hline DV & & Deliver & The number of resume delivery \\
\hline \multirow[t]{11}{*}{ IV } & \multirow{7}{*}{$\begin{array}{l}\text { Company } \\
\text { information }\end{array}$} & Scale & Number of employees \\
\hline & & Rank & General or advanced company certification \\
\hline & & Feedback & Company resume response rate \\
\hline & & Total & Total number of jobs posted by company \\
\hline & & Day & Number of days to join the website $* 30$ \\
\hline & & Identity & If true, the value is 1 , otherwise the value is 0 \\
\hline & & Picture & If true, the value is 1 , otherwise the value is 0 \\
\hline & \multirow{4}{*}{$\begin{array}{c}\text { Job } \\
\text { information }\end{array}$} & Wage & Minimum wages \\
\hline & & Welfare & Number of benefit labels \\
\hline & & Number & Number of recruits \\
\hline & & Experience & Job experience requirements \\
\hline
\end{tabular}

\section{Empirical results}

We collect data from 58.com. The reasons why we collect data from this website are as follows, first of all, 58.com is a comprehensive service website covering many fields. Its website includes various fields such as recruitment, real estate, automotive, finance, second-hand and local services, and has rich data resources. Second, 58.com has established a service network with direct contact with local merchants, the number of active local merchants on the current website More than 10 million. Finally, we can obtain many information for research through 58.com.

Table 2 Descriptive statistics.

\begin{tabular}{|c|c|c|c|c|c|}
\hline & $(1)$ & $(2)$ & $(3)$ & $(4)$ & $(5)$ \\
\hline VARIABLES & $\mathrm{N}$ & mean & sd & $\min$ & $\max$ \\
\hline Deliver & 3,482 & 20.79 & 63.98 & 0 & 2,161 \\
\hline Scale & 3,482 & 1.701 & 1.567 & 0 & 4 \\
\hline Rank & 3,482 & 0.0925 & 0.290 & 0 & 1 \\
\hline Total & 3,482 & 34.20 & 64.33 & 1 & 823 \\
\hline Day & 3,482 & 528.3 & 552.2 & 1 & 2,580 \\
\hline Identity & 3,482 & 0.605 & 0.489 & 0 & 1 \\
\hline Feedback & 3,482 & 0.466 & 0.339 & 0 & 1 \\
\hline Picture & 3,482 & 0.582 & 0.493 & 0 & 1 \\
\hline Wage & 3,482 & 6,150 & 3,783 & 2,200 & 80,000 \\
\hline Welfare & 3,482 & 4.532 & 2.476 & 0 & 14 \\
\hline Number & 3,482 & 12.39 & 34.04 & 1 & 999 \\
\hline Experience & 3,482 & 0.318 & 0.780 & 0 & 5 \\
\hline
\end{tabular}




\subsection{Data description}

A total of 4,130 recruitment data were collected from the sales work section of 58.com. Considering that the wages of the same kind of work will change due to regional structure and union differences, we chose Chengdu, Sichuan Province as the regional limitation. About 98\% of the recruited companies have passed the website's company certification. To verify how the factors, including scale and experience, influence the resume delivery behavior, we rated them according to categories. For scale of company, the range of level is $0-4$, the higher the level, the larger the scale of company. For experience requirements, the range of level is $0-5$, the higher the level, the higher the requirement. What's more, we cleaned the existing data to reduce the impact of noise. First, were moved the same values for company name, job name, job salary, and number of employees; Second, we filtered for null values; Finally, we filtered for outlier. A total of 3482 pieces of data were obtained after preprocessing. Descriptive statistics of the variables are shown in Table 2.

\subsection{Regression model}

Based on the distribution of the dependent variables, this study uses a Tobit regression model to perform hierarchical regression on the data. The reasons for using the Tobit model for regression are as follows. First, the range of the explanatory variables is limited. The minimum value is 0 and the maximum value is 2161 . About $96 \%$ of job resume delivery behavior is between 0 and 100 . The data distribution is tilted to the left. Second, the regression method is a useful analysis method for estimating the relationship between non-negative dependent variables and a set of independent variables. Tobit model can be used to solve the inherent selection bias. In order to reduce the impact of dimensions, we executed log-transformation for some variables. The model is as follows:

$$
\begin{aligned}
\text { Deliver }= & \alpha_{0}+\alpha_{1}{ }^{*} \text { Scale }+\alpha_{2}{ }^{*} \text { Rank }+\alpha_{3}{ }^{*} \text { Identity }+\alpha_{4}{ }^{*} \text { Feedback }+\alpha_{5}{ }^{*} \text { Total }+\alpha_{6}{ }^{*} \text { Day }+\alpha_{7}{ }^{*} \\
& \text { Picture }+\alpha_{8}{ }^{*} \text { lnWage }+\alpha_{9}{ }^{*} \text { Welfare }+\alpha_{10}{ }^{*} \text { lnNumber }+\alpha_{11}{ }^{*} \text { Experience }+\epsilon
\end{aligned}
$$

We choose two baseline models for comparison. Model1 only considers influential factor sin company information. On the basis of Model1, we further consider factors about job information.

Table 3 Results of regression.

\begin{tabular}{|c|c|c|}
\hline VARIABLES & Model1 & Model2 \\
\hline Scale & $-1.032^{* * *}$ & $-1.001^{* * *}$ \\
\hline Rank & 0.965 & 0.848 \\
\hline Total & $-0.047^{* * *}$ & $-0.048^{* * *}$ \\
\hline Day & $0.006^{* * *}$ & $0.006^{* * *}$ \\
\hline Identity & $2.059^{* * *}$ & $2.113^{* * *}$ \\
\hline Feedback & -1.15 & -1.031 \\
\hline Picture & $1.204^{* *}$ & $1.218^{* *}$ \\
\hline lnWage & & 0.578 \\
\hline Label & & -0.016 \\
\hline lnNumber & & $0.803^{* * *}$ \\
\hline Experience & & $1.394^{* * *}$ \\
\hline Constant & $5.949 * * *$ & -1.112 \\
\hline Pseudo R2 & 0.0250 & 0.0263 \\
\hline Observations & 3,482 & 3,482 \\
\hline \multicolumn{2}{|c|}{$* * * \mathrm{p}<0.01, * * \mathrm{p}<0.05, * \mathrm{p}<0.1$} \\
\hline \multicolumn{2}{|c}{}
\end{tabular}

\subsection{Hypotheses test}

The results of the model hypotheses test in this paper are shown in Table 3. The table shows that the number of employees of the company $(\mathrm{p}<0.01)$ and the total number of jobs posted by the company $(\mathrm{p}<0.01)$ have a significant negative effect on resume delivery behavior. What's more, the results show that the number of days to join the website $(p<0.01)$, identity $(p<0.01)$, and 
picture $(\mathrm{p}<0.05)$ exert significant positive influence on resume delivery behavior in company information, which are consistent with our hypothesis. In terms of job information, number of recruitments $(\mathrm{p}<0.01)$ and job experience requirements $(\mathrm{p}<0.01)$ have a significant positive effect on resume delivery behavior. This indicates that job-seekers are more likely to submit their resumes to positions that hire more recruits. Besides, there are less people who are qualified for the job as job experience requirements increase. Thus, those with rich job experience are inclined to submit their resumes to the positions that demand high experience. However, the empirical results reveal that wages and welfare have no significant effect on job-seekers' intentional behavior in online recruitment.

\section{Discussion}

In this study, we explore the factors that affect job applicants' resume delivery behavior from two aspects: company information and job information.

\subsection{Implications}

Our research makes multifold contributions through theoretical and managerialaspects. For theoretical implications, first, we identified multiple factors that influence the job-seekers' resume deliverybehavior in online recruitment. What's more, we expand the application of information quality toexplorethe effectiveness of the third-party online recruitment website from two perspectives: company information and job information. Finally, we make contributions to study from the perspective of a recruitment website where it contains various types of information (e.g., name, salary, location, etc.), which provides a new thought for study.

This study all contributes to the practice of management. First, the empirical results provide the third-party online recruitment websitewith advises that display as much detail as possibleinformation (e.g., scale, days, identity and so on) to ease job-seekers' uncertainty. Second, in the context of online recruitment, the content of some information posted on websites is exaggerated even completely inconsistent with reality. Therefore, it is necessary for the third-party recruitment website to verify the qualifications of the company and the information provided by the company. Finally, from the perspective of company, companies should improve their competitiveness in talent recruitment from the aspects of scale, identity, feedback, wage, welfare and so on. In the meantime, it's necessary for companies to provide accurate and truthful information.

\subsection{Limitations and future work}

The research in this paper has the following limitations: (1) In terms of research data, we use cross-section data to analyze the impact of information on job-seekers' intentional behavior at a certain time section, with time is not taken into account.(2) The impact of the company's textual description on the intentional behavior of job-seekers is not considered in this study. Future research can consider using panel data for continuous analysis, and use text mining methods to conduct in-depth analysis of the text descriptions and job requirements of the company.

\section{References}

[1] Banerjee, P.and Gupta, R. (2019) Talent Attraction through Online Recruitment Websites: Application of Web 2.0 Technologies. Australasian Journal of Information Systems, 23,1-23.

[2] Zusman, R. R. and Landis, R. S. (2002) Applicant preferences for web-based versus traditional job postings. Computers in Human behavior, 18(3), 285-296.

[3] Anand, J. and Devi, C. (2016) Literature review on e-recruitment and its perceived benefits: A walk towards paperless HR. IJAR, 2(11), 528-531.

[4] Kaur, P. (2015) E-recruitment: A conceptual study. International Journal of Applied Research, 1(8), 78-82. 
[5] Lane, T. S., Armin, J. and Gordon, J. S. (2015) Online recruitment methods for web-based and mobile health studies: a review of the literature. Journal of medical Internet research, 17(7), e183.

[6] Nasreem, S., Hassan, M. and Khan, T. A. (2016) Effectiveness of e-recruitment in small and medium enterprises of IT industry of Lahore (Pakistan). Pakistan Economic and Social Review, 54(1),143-164.

[7] Sultana, N. and Sultana, N. (2017) Analyzing the Effectiveness of Online Recruitment: A Case Study on Recruiters of Bangladesh. Asian Business Review, 7(2), 10-84.

[8] DeLone, W. H. and McLean, E. R. (1992) Information systems success: The quest for the dependent variable. Information systems research, 3(1), 60-95.

[9] Wang, R. Y. and Strong, D. M. (1996) Beyond accuracy: What data quality means to data consumers. Journal of management information systems, 12(4), 5-33.

[10] Alsultanny, Y. A. and Alotaibi, M. F. (2015) Evaluating the factors affecting on intension to use of e-recruitment. American Journal of Information Science and Computer Engineering, 1(5), 324-331.

[11] Parry, E. and Wilson, H. (2009)Factors influencing the adoption of online recruitment. Personnel Review, 38(6), 655-673.

[12] Nickel, J. and Schaumburg, H. (2004) Electronic privacy, trust and self-disclosure in e-recruitment. In CHI'04 Extended Abstracts on Human Factors in Computing Systems. ACM, 1231-1234.

[13] Cable, D. M. and Turban, D. (2001) Recruitment image equity: Establishing the dimensions, sources and value of job seekers' organizational beliefs. Research in personnel and human resources management, 20, 115-163.

[14] Cober, R. T., Brown, D. J., Keeping, L. M. and Levy, P. E. (2004) Recruitment on the net: How do organizational web site characteristics influence applicant attraction? Journal of Management, 30(5), 623-646.

[15] Collins, C. J. and Han, J. (2004) Exploring applicant pool quantity and quality: The effects of early recruitment practice strategies, corporate advertising, and firm reputation. Personnel psychology, 57(3), 685-717.

[16] Allen, D. G., SCOTTER, J. R. V. and Otondo, R. F. (2004) Recruitment communication media: Impact on prehire outcomes. Personnel Psychology, 57(1), 143-171.

[17] Carless, S. A.and Hetherington, K. (2011) Understanding the applicant recruitment experience: Does timeliness matter? International Journal of Selection and Assessment, 19(1), 105-108.

[18] Lee, Y. W., Strong, D. M., Kahn, B. K. and Wang, R. Y. (2002). AIMQ: a methodology for information quality assessment. Information \& management, 40(2), 133-146.

[19] Williamson, I. O., King Jr, J. E., Lepak, D. and Sarma, A. (2010) Firm reputation, recruitment web sites, and attracting applicants. Human Resource Management, 49(4), 669-687.

[20] Randolph, D. S. and Johnson, S. P. (2005) Predicting the effect of extrinsic and intrinsic job satisfaction factors on recruitment and retention of rehabilitation professionals. Journal of Healthcare management, 50(1), 49.

[21] Firfiray, S. and Mayo, M. (2017) The lure of work-life benefits: Perceived person-organization fit as a mechanism explaining job seeker attraction to organizations. Human Resource Management, 56(4), 629-649.

[22] Van Ours, J. and Ridder, G. (1991). Job requirements and the recruitment of new employees. Economics Letters, 36(2), 213-218.

[23] Menge, B. A. and Sutherland, J. P. (1987) Community regulation: variation in disturbance, competition, and predation in relation to environmental stress and recruitment. The American Naturalist, 130(5), 730-757. 